$$
\begin{aligned}
& a \cdot m \circ b=a m+b, \\
& (a+b)+c=a+(b+c), \\
& a+b=b+a, \\
& a+0=0+a=a, \\
& a+(-a)=(-a)+a=0,
\end{aligned}
$$$$
a(b+c)=a b+a c,
$$$$
(a+b) m=a m+b m \text {, }
$$$$
a 1=1 a=a \text {, }
$$$$
a a^{-1}=a^{-1} a=1, a \neq 0 \text {, }
$$$$
a^{-1}(a b)=b \text {. }
$$

If Theorem $\mathrm{L}$ holds for $A, B, M, N$ on three lines not in a pencil, then it is a universal theorem in $\pi$. In addition to (6.17.1) we also have (6.17.2) $(a b)^{-1}=b^{-1} a^{-1}$, $(b a) a^{-1}=b$ and any natural ring of $\pi$ is an alternative field. The collineation group of $\pi$ is transitive on the triangles of $\pi$.

Ohio State University,

Columbus, Оhiо

\title{
ERRATA, VOLUME 64
}

Don Mittleman, The unions of trajectorial series of lineal elements generated by the plane motion of a rigid body.

p. 503, line 2 of Theorem 1 . For " $(x, y)$ " read " $u(x, y)$. " 